\title{
АППАРАТ ДЛЯ ПОЛУЧЕНИЯ АКТИВИРОВАННОГО УГЛЯ НА МИНИ-ТЭС
}

\author{
Афанасьева Ольга Валерьевна', \\ eccolga@mail.ru
}

\author{
Мингалеева Гузель Рашидовна', \\ mingaleeva-gr@mail.ru
К Казанский государственный энергетический университет, Россия, 420066, Казань, ул. Красносельская, 51.

\begin{abstract}
Актуальность исследования обусловлена необходимостью разработки технологических решений и аппаратурного оформления производства побочных продуктов на объектах малой распределенной энергетики. Большинство описанных в литературе и представленных на рынке объектов малой энергетики ориентированы на получение тепловой и электрической энергии, т. е. на работу по принципу когенерации. Получение побочных продуктов путем термической переработки твердого топлива позволит оптимизировать систему производства тепловой и электрической энергии на мини-ТЭС, повысить эффективность использования топлива, решить экологические проблемы, а также обеспечить ценными химическими продуктами близлежащие районы и потребителей.

Цель: разработать конструкцию и провести расчет аппарата малой мощности для получения активированного угля на мини-ТЭС. объект: аппарат малой мощности для получения активированного угля путем термической переработки твердого углеродсодержащего сырья в кипящем слое.

Методы: гидродинамический расчет изотермических струй в кипящем слое, тепловой расчет, расчет параметров газораспределительной решетки.

Результаты. Разработана конструкция аппарата малой мощности для получения активированного угля на мини-ТЭС. В качестве прототипа установки выбрана конструкция реактора с кипящим слоем. Активатор представляет собой герметичный аппарат с перфорированной газораспределительной решеткой. Для рассматриваемого активатора выбрана наиболее простая перфорированная решетка с вертикальной ориентацией круглых отверстий, вогнутая к центру. Уголь поступает сверху через загрузочный патрубок и распределяется слоем на газораспределительной решетке, подача пара на активацию угля осуществляется в режиме струйного псевдоожижения через форсунки. Горячие газы, в качестве которых используются продукты сгорания топлива, подаются под решетку и приводят слой в псевдоожиженное состояние. Проведен гидродинамический и тепловой расчет аппарата, а именно определена критическая скорость начала псевдоожижения, степень расширения слоя, расход продуктов сгорания, расчет изотермической струи в псевдоожиженном слое, определены параметры газораспределительной решетки: длина газового факела струи, площадь живого сечения решетки.
\end{abstract}

\section{Ключевые слова:}

Объект малой распределенной энергетики, твердое топливо, побочные продукты, активированный уголь, активатор.

\section{Введение}

Объекты малой распределенной энергетики мини-ТЭС, производящие тепловую и электрическую энергию, являются оптимальным вариантом для обеспечения собственных нужд потребителей в энергоснабжении. Большинство данных объектов, представленных как типовые решения для внедрения и описанных в литературных источниках, ориентировано под использование природного газа, однако для многих регионов нашей страны, как и других стран, для производства энергии используется твердое топливо - уголь, торф, биомасса и промышленные отходы. В литературе представлено относительно небольшое количество технологических решений для работы мини-ТЭС на твердом топливе [1-4]. Среди них встречаются исследования и разработки, где помимо производства тепловой и электрической энергии рассматривается возможность получения ценной побочной продукции - активированного угля, полукокса, золошлаковых материалов, товарной серы [5-8].

Помимо экономического эффекта, когда реализация побочных продуктов позволяет стабилизиро- вать себестоимость производимой энергии на миниТЭС, решается и экологическая проблема использования твердого топлива. Экологическая составляющая до сих пор остается одним из сдерживающих факторов активного внедрения станций малой мощности, работающих на угле или другом виде твердого топлива, так как объекты распределенной генерации максимально близко располагаются к потребителям и выбросы вредных веществ должны иметь «нулевые» значения. Производство побочной продукции, в том числе путем утилизации вредных выбросов на мини-ТЭС, например, как в случае получения золошлаковых материалов из золы и шлака, позволит решить данную проблему.

Ввиду отсутствия широкого распространения объектов малой энергетики, работающих на твердом топливе, вопросы технологии получения из угля ценных побочных продуктов в условиях мини-ТЭС и серийного производства оборудования малой мощности, ориентированного на переработку твердого топлива, до конца не решены. В этой связи исследования, посвященные разработке технологий и аппаратов для термической переработки 
твердого топлива с целью получения побочных продуктов в условиях малых электростанций, являются актуальными и требуют тщательной проработки, что и являются целью данной работы.

\section{Получение активированного угля на мини-ТЭС}

На протяжении последних трех лет в нашей стране наблюдается подъем производства активированных углей. В 2017 г. в России было произведено 10468 т активированных углей, что на 10,8 \% выше объема производства предыдущего года [9]. Направления использования активированных углей охватывают различные отрасли промышленности, основными из которых являются: химическая (химические волокна, красители, химические реактивы), металлургическая (цветная и черная металлургия), газо- и нефтеперерабатывающая промышленность (разделение и очистка технологических потоков), очистка газовых выбросов (рекуперация растворителей, очистка газов) $[10,11]$.

Для получения активированного угля могут использоваться различные виды сырья: от традиционных - древесины, торфа, каменных и бурых углей, до скорлупы различных видов орехов, ячменной соломы, осадков сточных вод, жидкой нефтяной фракции, летучей золы, изношенных резиновых покрышек [12-16]. Несмотря на то, что в научных исследованиях последних лет все большее внимание уделяется нетрадиционным видам сырья, использование торфа, древесины и угольного топлива нашло наибольшее промышленное применение.

Проведенный анализ методов получения сорбентов из углеродсодержащего сырья показал возможность использованиякаменного угля, который является топливом при производстве тепловой и электрической энергии на малых автономных тепловых электростанциях, в качестве сырья для получения активированного угля.

Сортность угля является одним из основных показателей при выборе режимных параметров процесса активирования. Так, для углей с высоким содержанием смолы и летучих компонентов необходима предварительная обработка (измельчение, брикетирование, рассеивание, окисление) в виду их спекаемости при высоких температурах. Такие требования не предъявляются к антрациту, однако перед его активированием необходимо провести измельчение, брикетирование со связующим, повторное измельчение и уже затем карбонизацию и активирование. Угли с высоким содержанием летучих веществ перед активированием подвергают дроблению и промывке разбавленной минеральной кислотой (например, соляная, серная кислоты) [17].

Исследования, касающиеся процесса получения активированного угля из каменноугольного сырья, отражены в литературных источниках как российских, так и зарубежных авторов [18-20]. Процесс включает, как правило, проведение двух основных этапов - карбонизации и активирования. Известны химические и парогазовые методы активирования [21-23]. Для торфа и древесных опилок, которые являются некарбонизированными продуктами, предпочтительными являются методы химического активирования, а для карбонизированного сырья - каменных и древесных углей - парогазовое активирование. В качестве реагентов используется кислород, водяной пар и углекислый газ. Температура процесса достигает 800-1000 ${ }^{\circ} \mathrm{C}$, поэтому для его проведения необходимо специальное оборудование. Реакторы газового активирования должны удовлетворять следующим требованиям:

- обеспечивать интенсивное взаимодействие активирующих газов и углеродсодержащих веществ;

- поддерживать высокую температуру нагрева реакционного материала;

- обеспечивать эффективное использование тепловой энергии реакционного газа.

Всем этим показателям отвечают такие конструкций печей, как шахтные, многополочные, вращающиеся, а также реакторы с кипящим и движущимся слоем.

В рамках данной работыв качестве базовой модели выбран реактор с кипящим слоем. Эксплуатация подобных аппаратов обладает следующими несомненными преимуществами:

- подача сырья в реактор осуществляется непрерывно;

- интенсивное перемешивание и высокий коэффициент теплопередачи в слое обеспечивают изотермический режим в зоне реакции;

- температура в слое регулируется достаточно просто - за счет отвода тепла из зоны реакции;

- за счет интенсификации процесса сокращается время активирования;

- реактор данного типа имеет высокую производительность.

Реактор с кипящим слоем - герметичная цилиндрическая либо прямоугольная реакционная камера, в нижней части которой расположена газораспределительная решетка с отверстиями, через которые поступают газы на активацию. Форма и расположение отверстий, а также наличие различных вставок в газораспределительной решетке выбирается с учетом особенностей данного процесса.

Для разрабатываемого активатора выбрана наиболее простая перфорированная решетка с вертикальной ориентацией круглых отверстий, вогнутая к центру. При прохождении газораспределительного устройства формируются турбулентные струи ожижающего агента, которые приводят слой в псевдоожиженное состояние.

Условия взаимодействия фаз в слое зависят от таких параметров, как режим истечения, дальнобойность струй и степень их стесненности в прирешеточной зоне. Для поддержания режима псевдоожижения в слое и температуры $750-900{ }^{\circ} \mathrm{C}$ под газораспределительную решетку подаются продук- 
ты сгорания. Одновременно осуществляется подача пара на активацию в виде одной или нескольких струй через форсунки. За счет этого обеспечивается улучшение качества слоя и интенсификация тепло-массообменых процессов.

\section{Конструкция аппарата для получения активированного угля}

В данной работе представлена конструкция активатора, который может использоваться на угольной мини-ТЭС для получения активированного угля (рисунок).

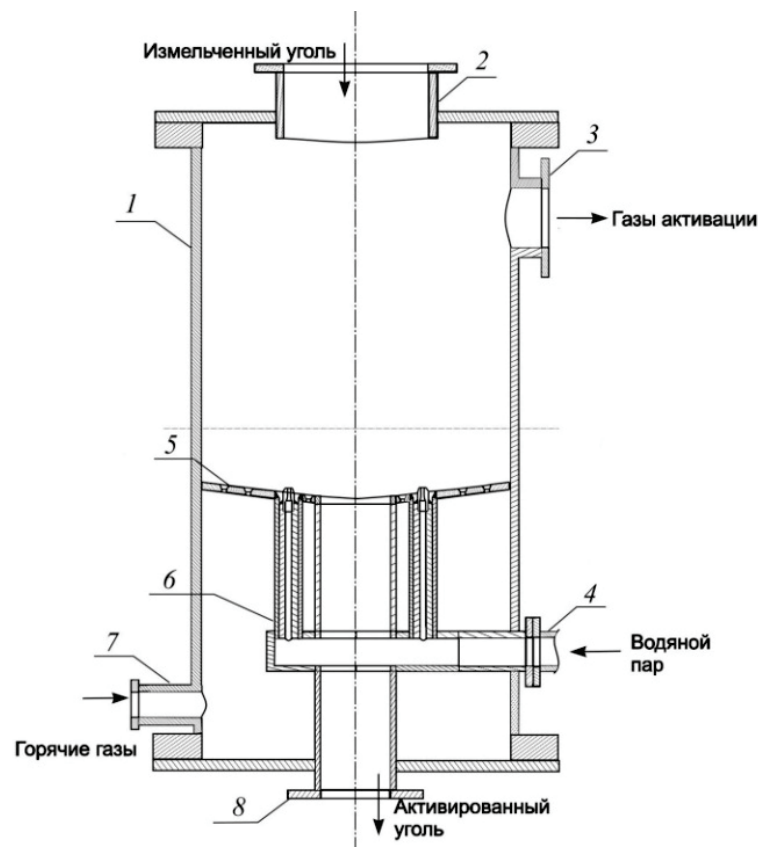

Рисунок. Активатор для производства активированного угля на мини-ТЭС: 1 - корпус; 2 - патрубок для подачи измельченного угля; 3 - патрубок для отвода газов активации; 4 - коллектор для подачи водяного пара; 5 - газораспреде лительная решетка; 6 - форсунки; 7 - патрубок для по дачи горячих газов; 8 - труба для отвода активированно 20 угля

Figure. Activator for production of activated carbon at mini thermal power plants: 1 is the case; 2 is the pipe for feeding crushed coal; 3 is the pipe for removal of activation gases; 4 is the collector for supplying water vapor; 5 is the gas distribution grid; 6 are the injectors; 7 is the pipe for supplying hot gases; 8 is the pipe for removal of activated carbon

Принцип работы аппарата следующий. Предварительно измельченный в углеразмольной молотковой мельнице и подсушенный уголь поступает через верхний загрузочный патрубок - 2 в активатор - 1 и распределяется слоем на газораспределительной решетке - 5. Под решетку подаются горячие газы, в качестве которых могут использоваться продукты сгорания топлива, полученные в специальной топке. Проходя через отверстия газораспределительной решетки, газы приводят слой в псевдоожиженное состояние. В результате теплообмена между газами и углем частицы угля нагрева- ются до температуры активации. В коллектор - 4, расположенный под решеткой, подается водяной пар, который через форсунки - 6 , установленные в отверстиях газораспределительной решетки, поступает в кипящий (псевдоожиженный) слой угля.

Форсунки в количестве 6 штук расположены в отверстиях газораспределительной решетки по окружности на равном расстоянии от центра активатора. Газораспределительная решетка содержит 48 отверстий, расположенных по трем концентрическим окружностям. На окружности наибольшего радиуса находится 24 отверстия, среднего - 16, наименьшего - 8 отверстий. При нагреве в парогазовой среде из частиц угля выделяются летучие и образуются микропоры. В результате образуется активированный уголь.

Образующиеся газы активации удаляются через боковой патрубок - 3, расположенный в верхней части активатора. Под действием силы тяжести частицы угля, поступающие сверху, постепенно перемещаются в нижнюю часть слоя. Время нахождения частиц в активаторе должно соответствовать времени активации угля. Для удаления готового активированного угля газораспределительная решетка имеет уклон к центру, за счет чего частицы скатываются в трубу -8 и отводятся из активатора при помощи шнека.

\section{Расчет реактора-активатора}

Расчет активатора включает следующие основные блоки: гидродинамический расчет, расчет изотермической струи в псевдоожиженном слое, тепловой расчет, расчет параметров газораспределительной решетки.

В табл. 1 представлены основные исходные данные для расчета.

Таблица 1. Исходные данные для расчета активатора

Table 1. Basic data for calculation of the activator

\begin{tabular}{|c|c|c|}
\hline $\begin{array}{l}\text { Наименование показателя } \\
\text { Indicator name }\end{array}$ & \begin{tabular}{|c|} 
Единицы измерения \\
Units \\
\end{tabular} & $\begin{array}{c}\text { Значение } \\
\text { Value }\end{array}$ \\
\hline $\begin{array}{l}\text { Производительность активатора } \\
\text { Activator performance }\end{array}$ & $\begin{array}{l}\mathrm{k \Gamma} / \mathrm{ч} \\
\mathrm{kg} / \mathrm{h}\end{array}$ & 226,8 \\
\hline \begin{tabular}{|l} 
Дисперсный состав угля \\
по фракциям (мм) \\
Dispersed composition \\
of coal fractions (mm) \\
$\quad 4-5$ \\
$3-4$ \\
$2-3$ \\
$\quad 1-2$ \\
$\quad 0,5-1$
\end{tabular} & $\%$ & $\begin{array}{c}1,0 \\
17,4 \\
56,2 \\
24,0 \\
1,4\end{array}$ \\
\hline $\begin{array}{l}\text { Температура в активаторе } \\
\text { Temperature in the activator }\end{array}$ & K & $1023-1173$ \\
\hline \begin{tabular}{|l|} 
Tемпература продуктов сгорания \\
Temperature of combustion products
\end{tabular} & K & 1473 \\
\hline $\begin{array}{l}\text { Время активации } \\
\text { Activation time }\end{array}$ & ч/h & $1-4$ \\
\hline $\begin{array}{l}\text { Начальная температура угля } \\
\text { Coal initial temperature } T_{\text {т }}^{\prime}\end{array}$ & K & 293 \\
\hline $\begin{array}{l}\text { Высота слоя } \\
\text { Layer height } H_{\text {сл0 }}\end{array}$ & $\mathrm{M} / \mathrm{m}$ & 0,5 \\
\hline
\end{tabular}


Гидродинамический расчет аппарата с кипящим (псевдоожиженным) слоем для получения активированного угля выполняется исходя из условия, что псевдоожижение в аппарате создается путем подвода горячих газов (продуктов сгорания) и подачи их в основные отверстия газораспределительной решетки [24].

1. Определяем эквивалентный диаметр частиц псевдоожиженного слоя, учитывая средний размер частиц каждой фракции $d_{i}$ и процентное массовое содержание частиц данной фракции $x_{i}$ :

$$
\frac{1}{d_{\ni}}=\sum \frac{x_{i}}{d_{i}} .
$$

2. Находим минимальное значение скорости газа, при которой обеспечивается интенсивное перемешивание частиц в кипящем слое, вычислив предварительно критерий Архимеда и критерий Рейнольдса.

Условия существования стационарного кипящего слоя: ограниченный интервал скоростей потока $u_{\mathrm{kp}}<u<u_{\text {вит }}$ от начала псевдоожижения до выноса всех частиц в трубу.

Критерий Архимеда определяется по формуле:

$$
\operatorname{Ar}=\frac{g \cdot d_{3}^{3}}{v_{\text {п.сг }}^{2}} \cdot \frac{\rho_{\text {т }}-\rho_{\text {п.сг }}}{\rho_{\text {п.сг }}},
$$

где $\rho_{\mathrm{r}}-$ плотность твердой фазы (исходного угля); $\rho_{\text {I.cr }}$ и $v_{\text {п.сг }}-$ плотность и кинематическая вязкость горячих газов соответственно.

3. Критическая скорость начала псевдоожижения определяется в зависимости от критерия Рейнольдса:

$$
u_{\mathrm{kp}}=\frac{\operatorname{Re}_{\mathrm{kp}} v_{\tilde{\mathrm{a}}}}{d_{ə}} .
$$

Критерий Рейнольдса вычисляется по найденному ранее критерию Архимеда:

$$
\mathrm{Re}_{\mathrm{rр}}=\frac{\mathrm{Ar}}{1400+5,22 \sqrt{\mathrm{Ar}}} .
$$

4. Для обеспечения интенсивного перемешивания в кипящем слое определяется оптимальная по теплообмену рабочая скорость потока:

$$
u_{\text {опт }}=\frac{\operatorname{Re}_{\text {т(опт) }} v_{\text {п.сг }}}{d} \text {, }
$$

где

$$
\operatorname{Re}_{\text {топт) }}=\frac{\mathrm{Ar}}{18+5,22 \sqrt{\mathrm{Ar}}} .
$$

5. Число псевдоожижения находим как отношение:

$$
n=\frac{u_{\text {опт }} .}{u_{\text {кр }}}
$$

6. Вычисляем критерий Рейнольдса для скорости витания частицы:

$$
\operatorname{Re}_{\text {вит }}=\frac{\mathrm{Ar}}{18+0,61 \sqrt{\mathrm{Ar}}} .
$$

7. Скорость витания частицы угля равна:

$$
u_{\text {вит }}=\frac{\operatorname{Re}_{\text {вит }} v_{\text {п.сгг }}}{d} .
$$

8. Определяем порозность слоя, применяя закон расширения однородного псевдоожиженного слоя, для оптимальной скорости частицы:

$$
\varepsilon_{\text {слл }}=\left(\frac{18 R e+0,36 \mathrm{Re}^{2}}{\mathrm{Ar}}\right)^{0,21} .
$$

9. Степень расширения слоя вычисляется по отношению:

$$
\frac{H_{\text {сл }}}{H_{\text {сло }}}=\frac{1-\varepsilon_{\text {сл } 0}}{1-\varepsilon_{\text {слл }}},
$$

где $H_{\text {сл0 }}$ и $\varepsilon_{\text {сл0 }}$ - высота и порозность неподвижного

\begin{tabular}{|c|c|}
\hline $\begin{array}{l}\text { Параметр } \\
\text { Parameter }\end{array}$ & $\begin{array}{l}\text { Значение } \\
\text { Value }\end{array}$ \\
\hline $\begin{array}{l}\text { Эквивалентный диаметр частиц } \\
\text { псевдоожиженного слоя, мм } \\
\text { Equivalent particle diameter of the fluidized bed, } \mathrm{mm}\end{array}$ & 2,12 \\
\hline $\begin{array}{l}\text { Критическая скорость начала псевдоожижения, м/с } \\
\text { Critical velocity of fluidization onset, m/s }\end{array}$ & 0,69 \\
\hline $\begin{array}{l}\text { Оптимальная по теплообмену рабочая скорость } \\
\text { потока } \mathrm{Re}_{m}, \mathrm{~m} / \mathrm{c} \\
\text { Optimum heat exchange working flow rate, } \mathrm{m} / \mathrm{s}\end{array}$ & 2,17 \\
\hline Число псевдоожижения/Fluidization number & 3,15 \\
\hline $\begin{array}{l}\text { Скорость витания частицы, м/с } \\
\text { Rate of particle movement, m/s }\end{array}$ & 1,54 \\
\hline Степень расширения слоя/Expansion layer $H_{\text {сл }} / H_{\text {сл0 }}$ & 1,224 \\
\hline $\begin{array}{l}\text { Расход продуктов сгорания } \dot{G}_{\mathrm{r}} \mathrm{\kappa г} /\left(\mathrm{m}^{2} \cdot \mathrm{c}\right) \\
\text { Consumption of combustion products, } \mathrm{kg} /\left(\mathrm{m}^{2} \cdot \mathrm{s}\right)\end{array}$ & 0,499 \\
\hline
\end{tabular}
слоя (до начала псевдоожижения); $H_{\text {сл }}$ - высота псевдоожиженного слоя.

10. Определяем расход ожижающего газа (продуктов сгорания) в расчете на $1 \mathrm{~m}^{2}$ площади поперечного сечения аппарата, кг $/\left(\mathrm{M}^{2} \cdot \mathrm{c}\right)$ :

$$
\dot{G}_{\text {г }}=u_{\text {опт }} \rho_{\text {п.сг }} \text {. }
$$

Результаты расчета представлены в табл. 2.

таблица 2. Результаты гидродинамического расчета Table 2. Results of hydrodynamic calculation

Расчет изотермической струи в псевдоожиженном слое угля проводится по методике Буевича Ю.А., исходя из условия подачи водяного пара в виде отдельных струй в предварительно ожиженный слой частиц угля [25].

1. Вычисляем критерий Архимеда для частицы угля в потоке пара:

$$
\operatorname{Ar}=\frac{g \cdot d_{3}^{3}}{v_{\mathrm{II}}^{2}} \cdot \frac{\rho_{\mathrm{T}}-\rho_{\mathrm{II}}}{\rho_{\mathrm{II}}},
$$

где $\rho_{\text {п }}$ и $v_{\text {п }}$ - плотность и кинематическая вязкость водяного пара при заданных температуре и давлении соответственно.

2. Определяем скорость на границе газового факела:

$$
U_{\mathrm{B}}=\frac{\eta \frac{A r}{18+0,61 \sqrt{\mathrm{Ar}}} v}{d_{ə}},
$$

где $\eta=0,8$ для всех струй. 
3. Критерий Галилея рассчитываем по эквивалентному диаметру частиц угля:

$$
\mathrm{Ga}=\frac{g d_{3}^{3}}{v^{2}} .
$$

4. Коэффициент струи $C_{1}$ определяется по формуле:

$$
C_{1}=0,46 \mathrm{Ga}^{0,1} .
$$

5. Средняя плотность зоны «газ - твердые частицы» может быть рассчитана по приближенной зависимости:

$$
\rho_{\mathrm{\pi}}^{\prime} / \rho_{\mathrm{\pi}_{0}}=0,34-0,035 d_{3} .
$$

6. Коэффициент $C_{2}$ определяется в зависимости от $C_{1}$ и средней плотности зоны «газ - твердые частицы»:

$$
C_{2}=C_{1} \sqrt{\rho_{\mathrm{r}} / \rho_{\mathrm{II}}^{\prime}} .
$$

7. Длина газового факела струи рассчитывается по соотношению:

$$
Y_{\phi}=\frac{U_{0} r_{0}}{0,366 U_{\mathrm{B}} C_{1}},
$$

где $U_{0}$ - скорость истечения пара из отверстия, м/с; $r_{0}$ - радиус отверстия, м.

8. Определяем абсциссу начального сечения факела струи:

$$
Y_{\text {н }}=1,75 r_{0} / C_{1} .
$$

9. Определяем абсциссу переходного сечения факела струи:

$$
Y_{\text {I }}=3,28 r_{0} / C_{1} .
$$

\begin{tabular}{|c|c|}
\hline $\begin{array}{l}\text { Параметр } \\
\text { Parameter }\end{array}$ & $\begin{array}{c}\text { Значение } \\
\text { Value }\end{array}$ \\
\hline $\begin{array}{l}\text { Критерий Архимеда для частицы угля в потоке пара } \\
\text { Archimedes criterion for coal particles in steam flow }\end{array}$ & $7,72 \cdot 10^{3}$ \\
\hline $\begin{array}{l}\text { Скорость на границе газового факела, м/с } \\
\text { Speed at the gas torch border, m/s }\end{array}$ & 2,76 \\
\hline Критерий Галилея/Galilean criterion & 20,2 \\
\hline \begin{tabular}{|c} 
Коэффициент струи/Jet ratio: \\
$C_{1}$ \\
$C_{2}$
\end{tabular} & $\begin{array}{l}0,62 \\
0,04\end{array}$ \\
\hline $\begin{array}{l}\text { Длина газового факела струи, мм } \\
\text { Length of the gas jet torch, mm }\end{array}$ & 1277 \\
\hline $\begin{array}{r}\text { Абсцисса/Abscissa: } \\
\text { начального сечения, мм/initial section, mm } \\
\text { переходного сечения, Mм/cross section, mm }\end{array}$ & $\begin{array}{l}28,2 \\
52,9\end{array}$ \\
\hline $\begin{array}{l}\text { Безразмерная осевая скорость в газовом факеле } \\
\text { круглой струи } \\
\text { Dimensionless axial velocity in a gas jet of a circular jet }\end{array}$ & 0,2 \\
\hline
\end{tabular}

Результаты расчета по формулам (13)-(21) приведены в табл. 3.

Таблица 3. Результаты расчета изотермической струи в псевдоожиженном слое

Table 3. Results of calculation of the isothermal jet in the fluidized bed

10. Для ряда значений скорости на оси струи $U_{m i}$ (от $0,835 U_{0}$ до $U_{\text {в }}$ ) при известных $U_{\mathrm{B}}, C_{1}, C_{2}$ и $\rho_{\text {п }}$ рассчитываем среднюю плотность сечения струи $\rho_{\text {ср }}$ и толщину пограничного слоя $b_{i}$ :

$$
\begin{gathered}
\sqrt{\frac{\rho_{\mathrm{cp}}}{\rho_{0}}}=\frac{C_{1}}{C_{1} \cdot \grave{A}+C_{2}}, \\
b_{i}=\frac{U_{0} r_{0}}{0,366 \sqrt{\rho_{\mathrm{cp}} / \rho_{0}} U_{m_{i}}},
\end{gathered}
$$

где $U_{m}$ определяется по эмпирическим зависимостям; параметр $A$ вычисляется по соотношению:

$$
A=\frac{U_{m}-U_{\mathrm{B}}}{U_{m}+U_{\mathrm{B}}} .
$$

11. Толщина факела струи в различных сечениях струи определяется по формуле:

$$
b_{\Phi_{\mathrm{y}}}=\frac{U_{m}-U_{\mathrm{B}}}{U_{m}-U_{\mathrm{B}}} C_{1} y,
$$

где $y$ - высота струи, т. е. расстояние от выхода до

\begin{tabular}{|c|c|c|c|c|c|c|}
\hline \multirow{2}{*}{$\begin{array}{c}U_{m}, \mathrm{M} / \mathrm{c} \\
(\mathrm{m} / \mathrm{s})\end{array}$} & \multirow{2}{*}{$U_{m} / U_{0}$} & \multirow{2}{*}{ A } & \multirow{2}{*}{$\begin{array}{c}\rho_{\mathrm{cp}}, \mathrm{K} \Gamma / \mathrm{M}^{3} \\
\left(\mathrm{~kg} / \mathrm{m}^{3}\right)\end{array}$} & $b_{i}$ & $y_{i}$ & $b_{\phi i}$ \\
\hline & & & & \multicolumn{3}{|c|}{$\mathrm{MM} / \mathrm{mm}$} \\
\hline 66,8 & 0,835 & 0,92 & 0,43 & 32,34 & 52,98 & 30,22 \\
\hline 40 & 0,5 & 0,87 & 0,48 & 51,12 & 88,22 & 47,59 \\
\hline 30 & 0,38 & 0,83 & 0,52 & 65,48 & 118,07 & 60,76 \\
\hline 20 & 0,25 & 0,76 & 0,62 & 89,95 & 175,96 & 82,91 \\
\hline 10 & 0,13 & 0,57 & 1,05 & 138,24 & 351,40 & 124,19 \\
\hline 3 & 0,04 & 0,04 & 37,25 & 77,37 & 1193,92 & 29,61 \\
\hline
\end{tabular}
$i$-го сечения струи по вертикали.

12. Определяем профиль скорости в газовом факеле струи:

$$
\Delta U / \Delta U_{m}=1-\left[1-\left(1-x / b_{\phi}\right)^{1,5}\right]^{2},
$$

где $x$ - расстояние от оси струи по горизонтали.

Результаты расчетов по формулам (22)-(26) представлены в табл. 4.

таблица 4. Результаты расчетов основных параметров струи Table 4. Results of calculations of the jet main parameters

Результаты определения профиля скорости в газовом факеле струи приведены в табл. 5.

Таблица 5. Результаты расчетов профиля скорости в факеле cmpyu

Table 5. Results of calculations of the velocity profile in the jet plume

\begin{tabular}{|c|c|c|c|c|c|c|c|c|}
\hline$x, \mathrm{MM} / \mathrm{mm}$ & 0 & 10 & 20 & 40 & 60 & 80 & 100 & 120 \\
\hline$\Delta U / \Delta U_{m}$ & 1 & 0,986 & 0,946 & 0,805 & 0,605 & 0,379 & 0,165 & 0,012 \\
\hline$\Delta U, \mathrm{M} / \mathrm{c}(\mathrm{m} / \mathrm{s})$ & 120 & 118,3 & 113,5 & 96,6 & 72,6 & 45,5 & 19,8 & 1,44 \\
\hline $\begin{array}{c}U=\Delta U+U_{\mathrm{B}}, \\
\mathrm{M} / \mathrm{c}(\mathrm{m} / \mathrm{s})\end{array}$ & 122,8 & 121,1 & 116,3 & 99,4 & 75,4 & 48,2 & 22,6 & 4,2 \\
\hline
\end{tabular}

Тепловой расчет аппарата для производства активированного угля проводится на основе теплового баланса аппарата, в который входят следующие составляющие:

$$
Q_{\mathrm{y}}+Q_{\text {исп }}+Q_{\text {пв вх }}+Q_{\text {псг }}+Q_{\mathrm{x} . \mathrm{p}}=Q_{\text {пак }}+Q_{\mathrm{ay}}+\Delta Q_{\text {пот }},
$$

которые могут быть определены по следующим формулам: 
- теплота поступающего угля

$$
Q_{\mathrm{y}}=G_{\mathrm{T}} \cdot Q_{\mathrm{H}}^{\mathrm{p}} \cdot\left(\frac{1+W^{\mathrm{p}}}{100}\right) ;
$$

- теплота испарения влаги угля

$$
Q_{\text {исп }}=G_{\mathrm{T}} \cdot\left(\frac{W_{\text {физ }}^{\mathrm{p}}}{100}\right) \varphi \cdot c_{\text {исп вл }} \cdot T ;
$$

- теплота поступающего водяного пара

$$
Q_{\text {пв }}=G_{\text {п }} \cdot C_{\text {пा }} \cdot T \text {; }
$$

- теплота паров активации

$$
Q_{\text {пак }}=G_{\text {па а }} \cdot C_{\text {п }} \cdot T+G_{\text {т }} \cdot \frac{V^{\mathrm{T}}}{100} \cdot C_{\text {лет }} \cdot T_{\text {лет }} ;
$$

- теплота образующегося активированного угля

$$
Q_{\mathrm{ay}}=G_{\mathrm{t}}\left(1-\frac{V^{\mathrm{r}}}{100}\right) \cdot Q_{\mathrm{r}}^{\mathrm{p}} \cdot\left(\frac{1+W^{\mathrm{p}}}{100}\right) ;
$$

- теплота химических реакций активации

$$
Q_{\mathrm{x} . \mathrm{p}}=G_{\mathrm{T}} \cdot \Delta H_{\mathrm{x} . \mathrm{p}} ;
$$

- теплота продуктов сгорания

$$
\left.Q_{\text {псг }}=\left(Q_{\text {пак }}+Q_{\text {ау }} \pm Q_{\text {х.р }}+\Delta Q\right)-Q_{\text {т }}-Q_{\text {исп }}\right) \text {; }
$$

- расход продуктов сгорания

$$
G_{\text {п сг }}=\frac{Q_{\text {псг }}}{C_{\text {п сг }} \cdot T_{\text {п сг }}} .
$$

В формулах (27)-(34) используются следующие величины: $G_{\text {т }}$ - расход угля на активацию, кг/с; $Q_{\mathrm{H}}^{\mathrm{p}}$ - низшая теплотворная способность рабочего топлива, кДж/кг; $W^{\text {p }}$ - влажность угля на рабочую массу; $W_{\text {физ }}^{\mathrm{p}}$ - влажность угля на рабочую массу; $c_{\text {исввл }}, T-$ теплоемкость и температура испаренной влаги соответственно, кДж/(кг.К), $K$; $V^{\text {r }}$ - выход летучих, $\% ; c_{\text {лет }}, T_{\text {лет }}-$ теплоемкость и температура летучих соответственно, кДж/(кг·К), $K$; $Q_{\kappa}^{p}-$ низшая теплота сгорания активированного угля (кокса); $Q_{\text {х.р }}$ - теплота химических реакций, Дж/с; $\Delta Q_{\text {пот }}$ потери, Дж/с; $\Delta H_{\text {х.р }}$ - теплота химических реакций в аппарате, Дж/кг; $\varphi$ - доля физически связанной влаги, которая участвует в образовании летучих. Результаты теплового расчета приведены в табл. 6 . Расход продуктов сгорания составляет 0,33 кг/с.

Таблица 6. Результаты теплового расчета

Table 6. Results of thermal calculation

\begin{tabular}{|l|c|}
\multicolumn{1}{|c|}{$\begin{array}{l}\text { Параметр } \\
\text { Рarameter }\end{array}$} & $\begin{array}{c}\text { Значение, кДж/c } \\
\text { Value, kJ/s }\end{array}$ \\
\hline Теплота поступаюего угля/Incoming coal heat & 1512 \\
\hline $\begin{array}{l}\text { Теплота испарения влаги угля } \\
\text { Coal moisture evaporation heat }\end{array}$ & 19 \\
\hline $\begin{array}{l}\text { Tеплота поступающего водяного пара } \\
\text { Incoming steam heat }\end{array}$ & 65 \\
\hline Tеплота паров активации/Activation vapor heat & 87 \\
\hline $\begin{array}{l}\text { Tеплота образующегося активированного угля } \\
\text { Generated activated саrbon heat }\end{array}$ & 1323 \\
\hline $\begin{array}{l}\text { Теплота химических реакций активации } \\
\text { Сhemical activation reaction heat }\end{array}$ & 517 \\
\hline $\begin{array}{l}\text { Теплота продуктов сгорания } \\
\text { Сombustion products heat }\end{array}$ & 596 \\
\hline
\end{tabular}

Результаты расчетов, представленные в табл. 2-6, позволяют определить конструктивные и режимные параметры аппарата для получения активированного угля, а также характеристики вспомогательного оборудования.

По расчетной оценочной формуле, предложенной О.М. Тодесом и О.Б.Читовичем, определяем коэффициент температуропроводности кипящего слоя [24]:

$$
a=D_{\text {см }}=\frac{1}{60} \sqrt{g L^{3}}\left(\frac{u}{u_{\text {кр }}}-1\right) .
$$

С учетом того, что в формуле (35) $L$ - это длина аппарата, а в активаторе в качестве линейной (геометрической) характеристики используется высота слоя $H_{\text {сл }}$, данное уравнение представим в следующем виде:

$$
a=D_{\text {см }}=\frac{1}{60} \sqrt{g H_{\text {сл } 0}^{3}}\left(\frac{u_{\text {опт }}}{u_{\text {кр }}}-1\right) .
$$

Расчет параметров газораспределительной решетки проводится по формулам (1)-(19) с учетом того, что под газораспределительную решетку подается горячий газ (продукты сгорания) и параметры пара в данных формулах заменяются на параметры газа.

По определенному из теплового баланса расходу продуктов сгорания рассчитывается площадь живого сечения газораспределительной решетки:

\begin{tabular}{|c|c|}
\hline $\begin{array}{l}\text { Параметр } \\
\text { Parameter }\end{array}$ & $\begin{array}{l}\text { Значение } \\
\text { Value }\end{array}$ \\
\hline $\begin{array}{l}\text { Эффективный коэффициент температуропроводности } \\
\text { Effective coefficient of thermal diffusivity }\end{array}$ & 0,16 \\
\hline $\begin{array}{l}\text { Критерий Архимеда для частицы угля в потоке газа } \\
\text { Archimedes criterion for coal particles in a gas stream }\end{array}$ & $1,4 \cdot 10^{4}$ \\
\hline $\begin{array}{l}\text { Скорость на границе газового факела, м/с } \\
\text { Speed at the gas torch border, m/s }\end{array}$ & 12,33 \\
\hline Критерий Галилея/Galilean criterion & 21,1 \\
\hline Коэффициент струи/Jet ratio $C_{1}$ & 0,62 \\
\hline $\begin{array}{l}\text { Средняя плотность зоны «газ - твердые частицы», кг/м } \mathrm{m}^{3} \\
\text { Average density of the zone «gas - solid particles», } \mathrm{kg} / \mathrm{m}^{3}\end{array}$ & 0,06 \\
\hline Коэффициент/Coefficient $C_{2}$ & 0,04 \\
\hline $\begin{array}{l}\text { Длина газового факела струи, мм } \\
\text { Length of the gas jet torch, mm }\end{array}$ & 285 \\
\hline $\begin{array}{l}\text { Площадь живого сечения решетки, }{ }^{2} \\
\text { Area of the lattice living section, } \mathrm{m}^{2}\end{array}$ & 0,018 \\
\hline
\end{tabular}

$$
F_{\text {сеч }}=\frac{G_{\text {псг }}}{\mathrm{U}_{0} \cdot \rho_{\text {п сг }}} .
$$

На основе полученного значения живого сечения решетки выбирается количество и диаметр отверстий ( $N_{\text {отв }}=48, d_{\text {отв }}=22$ мм). Результаты расчета представлены в табл. 7.

таблица 7. Результаты расчета паралетров газораспределительной решетки

Table 7. Results of calculation of the gas distribution grid parameters 


\section{Заключение и выводы}

Представлена конструкция аппарата для получения активированного угля в условиях малых энергетических объектов. Произведен расчет гидродинамических параметров, расчет параметров газораспределительной решетки и тепловой расчет процесса активирования. Получены значения основных конструктивных параметров аппарата при произво-

\section{СПИСОК ЛИТЕРАТУРЫ}

1. Duffy T.E., Director P.E., Schneider P.H. Advanced combinedcycle from 8 MW to 23 MW // Proc. Amer. Power. Conf. - Chicago, 1993. - P. 1733-1741.

2. Данилевич Я.Б., Боченинский В.П., Кириченко Б.Э., Коваленко А.Н. Малые электростанции: ОЭЭП РАН. - СПб.: Изд-во СПбГТУ, 2002. - 30 c.

3. Мини-ТЭЦ на базе обращенного газогенератора / А.М. Дубинин, Е.В. Черепанова, В.Г. Тупоногов, О.А. Обожин // Теплоэнергетика. - 2010. - № 6. - С. 29-32.

4. Малая тепловая электростанция повышенной эффективности Я.Б. Данилевич, А.С. Делюкин, Б.Э. Кириченко, А.Н. Коваленко, В.Л. Шилин // Известия АН. Энергетика. - 2003. № 1. - C. 148-153.

5. Проблемы создания отечественных мини-ТЭЦ / Т.А. Борк, В.П. Вершинский, И.П. Евтюхова, Н.М. Коробов, З.П. Сорокина // Теплоэнергетика. - 1991. - № 10. - С. 18-21.

6. Котлер В.Р. Мини-ТЭЦ: зарубежный опыт // Теплоэнергетика. - 2006. - № 8. - С. 69-71.

7. Afanasyeva 0.V., Mingaleeva G.R. Comprehensive exergy analysis of the efficiencyof a low-capacity power plant with coal gasification and obtaining sulfur // Energy Efficiency. - 2015. V. 8. - Iss. 2. - P. 255-265.

8. Афанасьева 0.В., Мингалеева Г.Р. Моделирование технологических схем мини-ТЭС. - М.: ИД МЭИ, 2014. - 220 с.

9. Рынок активированного угля. Текущая ситуация и прогноз 2018-2022 гг. URL: http://alto-group.ru/otchot/marketing/326-rynok-aktivirovannogo-uglya-tekushhaya-situaciya-iprognoz-2014-2018-gg.html (дата обращения: 05.07.2018).

10. Место активных углей в экологии и экономике. Новые технологии их производства / В.М. Мухин, А.А. Курилкин, Н.Л. Воропаева, К.В. Лексюкова, П.В. Учанов // Сорбционные и хроматографические процессы. - 2016. - Т. 16. - № 3. C. $346-353$.

11. Moreno-Piraján J.C., Bastidas-Barranco M.J., Giraldo L. Preparation of activated carbons for storage of methane and its study by adsorption calorimetry //Journal of Thermal Analysis and Calorimetry. - 2018. - V. 131. - Iss. 1.- P. 259-271.

12. Production of activated carbon from peat by with natural soda ash and effect of nitrogen addition on the development of surface area / N. Tsubouchi, M. Nishio, Y. Shinohara, J. Bud, Y. Mochizuki // Fuel Processing Technology. - 2018. - V. 176. - P. 76-84.

13. Получение гранулированного активного угля из отходов растительного сырья / Е.А. Фарберова, Е.А. Тиньгаева, А.Д. Чучалина, А.Р. Кобелева, А.С. Максимов // Известия высших дительности по активированному углю 226,8 кг/ч. Габариты аппарата позволяют разместить его на небольшой площади в условиях мини-ТЭС и использовать при снижении потребности в тепловой и электрической энергии, а также выровнять график загрузки автономного энергетического объекта.

Исследование выполнено при финансовой поддержке РФФИ в рамках научного проекта № 17-08-00295 «А».

учебных заведений. Серия: Химия и химическая технология. - 2018. - Т. 61 (3). - С. 51-57.

14. Preparation of activated carbon from lignin by chemical activation / J. Hayashi, A. Kazehaya, K. Muroyama, A.P. Watkinson // Carbon. - 2000. - № 38 (13). - P. 1873-1878.

15. Activated carbons from used motor oil as catalyst support for sustainable environmental protection / T. Tsoncheva, A. Mileva, S.P. Marinov, D. Paneva, N. Velinov, I. Spassova, A. Kosateva, D. Kovacheva, N. Petrov // Microporous and Mesoporous Materials. - 2018. - V. 259. - P. 9-16.

16. Pallarés J., González-Cencerrado A., Arauzo I. Production and characterization of activated carbon from barley straw by physical activation with carbon dioxide and steam // Biomass and Bioenergy. - 2018. - V. 115. - P. 64-73.

17. Кинле Х., Бадер Э. Активные угли и их промышленное применение / Пер. с немецкого. - Л.: Химия, 1984. - 216 с.

18. Akash B.A., O'Brien W.S. The production of activated carbon from a bituminous coal // International Journal of Energy Research. - 1996. - V. 20. - Iss. 10. - P. 913-922.

19. Wilson J. Active carbons from coals // Fuel. - 1981. - V. 60. Iss. 9. - P. 823-831.

20. Исследование процесса получения активированного угля из каменноугольного сырья и возможности использования побочных продуктов / Е.Н. Нуруллина, М.В. Шулаев, М.Р. Якубов, А.С. Сироткин, А.М. Гумеров // Вестник технологического университета. - 2012. - Т. 15. - В. 12. - С. 237-241.

21. Оптимальное управление производством активного угля во вращающихся печах / В.Ф. Олонцев, Е.А. Фарберова, К.С. Белоусов, Е.А. Тиньгаева // Вестник ПНИПУ. - 2015. - № 3. C. $51-59$.

22. Preparation of activated carbons from bituminous coals with $\mathrm{CO}_{2}$ activation. 1. Effects of oxygen content in raw coals / H. Teng, J.-A. Ho, Y.-F. Hsu, C.-T. Hsieh // Industrial and Engineering Chemistry Research. - 1996. - № 35 (11). P. 4043-4049.

23. Improvement of Activated Carbon from Jixi Bituminous Coal by Air Preoxidation / D. Liu, J. Gao, Q. Cao, S. Wu, Y. Qin // Energy and Fuels. - 2017. - V. 31. - Iss. 2. - P. 1406-1415.

24. Тодес 0.М., Цитович 0.Б. Аппараты с кипящим зернистым слоем (гидравлические и тепловые основы работы). - Л.: Химия, 1981. -296 с

25. Буевич Ю.А., Минаев Г.А. Струйное псевдоожижение. - М.: Химия, 1984. - 133 с.

Поступила 27.08.2019 г.

\section{Информация об авторах}

Афанасьева O.B., кандидат технических наук, начальник Управления научных исследований, инноваций и разработок, доцент кафедры энергетического машиностроения Казанского государственного энергетического университета.

Мингалеева Г.P., доктор технических наук, заведующий кафедрой энергетического машиностроения Казанского государственного энергетического университета. 
UDC 661.183.2: 662.742

\title{
APPARATUS FOR RECEIVING ACTIVATED COAL AT MINI THERMAL POWER PLANTS
}

\author{
Olga V. Afanaseva', \\ eccolga@mail.ru
}

\author{
Guzel R. Mingaleeva', \\ mingaleeva-gr@mail.ru \\ 'Kazan State Power Engineering University,
51, Krasnoselskaya street, Kazan, 420066, Russia.
}

The relevance of the research is caused by the need to develop technological solutions and hardware design for production of by-products at small distributed energy facilities. The majority of small energy objects described in the literature and presented on the market are focused on generation of heat and electrical energy, i.e. on operation of the cogeneration principle. Obtaining by-products by thermal processing of solid fuels allows optimizing the system for production of heat and electricity at mini thermal power plants, improving fuel efficiency, solving environmental problems, and providing valuable chemical products to nearby areas and consumers.

The main aim of the research is to develop the design and carry out the calculation of the apparatus of low power to obtain activated carbon at mini thermal power plants.

object: the apparatus of low power for obtaining activated carbon by thermal processing of solid carbon-containing raw materials in the fluidized bed.

Methods: hydrodynamic calculation of non-isothermal jets in a fluidized bed, heat calculation, calculation of parameters of the gas distribution grid.

Results. The authors have developed the design of a low-power apparatus for producing activated carbon at mini thermal power plant and chose the design of a fluidized bed reactor as a prototype of the installation. The activator is a sealed apparatus with a perforated gas distribution grid. For the considered activator, the simplest perforated grating with a vertical orientation of round holes concave toward the center was chosen. Coal enters from the top through the loading nozzle and is distributed by a layer on the gas distribution grid, steam is supplied to the activation of coal in a jet fluidization mode through the nozzles. Hot gases - the products of fuel combustion - are fed under the grate and bring the layer into a fluidized state. The authors carried out the hydrodynamic and thermal calculations of the apparatus, namely, they determined the critical velocity of the onset of fluidization, the degree of expansion of the bed, the flow rate of combustion products, the calculation of the isothermal jet in the fluidized bed, the parameters of the gas distribution grid: the length of the gas jet, the area of the cross section of the lattice.

\section{Key words:}

Object of small distributed energy, solid fuel, by-products, activated carbon, activator.

The research was financially supported by the RFBR within the scientific project no. 17-08-00295 «A».

\section{REFERENCES}

1. Duffy T.E., Director P.E., Schneider P.H. Advanced combinedcycle from $8 \mathrm{MW}$ to $23 \mathrm{MW}$. Proc. Amer. Power. Conf. Chicago, 1993. pp. 1733-1741.

2. Danilevich Ya.B., Bocheninsky V.P., Kirichenko B.E., Kovalenko A.N. Small power plants: OEEP RAS. St. Petersburg, SPSTU Publ., 2002. $32 \mathrm{p}$.

3. Dubinin A.M., Cherepanova E.V., Tuponogov V.G., Obozhin 0.A. Mini-tec na baze obrashchennogo gazogeneratora [Mini-TES on the basis of a reversed gas generator]. Teploenergetika, 2010, no. 6, pp. 29-32.

4. Danilevich Ya.B., Delyukin A.S., Kirichenko B.E., Kovalenko A.N., Shilin V.L. Malaya teplovaya elektrostantsiya povyshennoy effektivnosti [Small thermal power plant of increased efficiency]. Izvestiya AN. Energetika, 2003, no. 1, pp. 148-153.

5. Bork T.A., Vershinsky V.P., Evtyukhova I.P., Korobov N.M., Sorokina Z.P. Problemy sozdaniya otechestvennykh mini-TES [Problems of creating domestic mini-TES]. Teploenergetika, 1991, no. 10, pp. 18-21.

6. Kotler V.R. Mini-TES: zarubezhny opyt [Mini-TES: foreign experience]. Teploenergetika, 2006, no. 8, pp. 69-71.

7. Afanasyeva 0.V., Mingaleeva G.R. Comprehensive exergy analysis of the efficiency of a low-capacity power plant with coal gasification and obtaining sulfur. Energy Efficiency, 2015, vol. 8, Iss. 2, pp. 255-265.

8. Afanasyeva 0.V., Mingaleeva G.R. Modelirovanie tekhnologicheskikh skhem mini-TES [Modeling of technological schemes of mini-thermal power plants]. Moscow, MEI Publ., 2014. 220 p.
9. Rynok aktivirovannogo uglya. Tekushchaya situatsiya i prognoz 2018-2022 [The market of activated carbon. Current situation and forecast 2018-2022]. Available at: http://alto-group.ru/ otchot/marketing/326-rynok-aktivirovannogo-uglya-tekushhayasituaciya-i-prognoz-2014-2018-gg.html (accessed 5 July 2018).

10. Mukhin V.M., Kurilkin A.A., Voropaeva N.L., Leksyukova K.V., Uchanov P.V. Mesto aktivnykh ugley v ekologii i ekonomike. Novye tekhnologii ikh proizvodstva [The place of active coals in ecology and economics. New technologies for their production]. Sorption and chromatographic processes, 2016, no. 3, pp. 346-353.

11. Moreno-Piraján J.C., Bastidas-Barranco M.J., Giraldo L. Preparation of activated carbons for storage of methane and its study by adsorption calorimetry. Journal of Thermal Analysis and Calorimetry, 2018, vol. 131, Iss. 1, pp. 259-271.

12. Tsubouchi N., Nishio M., Shinohara Y., Bud J., Mochizuki Y. Production of activated carbon from peat by natural soda ash and effect of nitrogen. Fuel Processing Technology, 2018, vol. 176, pp. $76-84$.

13. Farberova E.A., Tingaeva E.A., Chuchalina A.D., Kobeleva A.R., Maximov A.S. Poluchenie granulirovannogo aktivnogo uglya iz otkhodov rastitelnogo syrya [Obtaining granulated active carbon from wastes of vegetable raw materials]. Izvestiya Vysshikh Uchebnykh Zavedenii, Seriya Khimiyai Khimicheskaya Tekhnologiya, 2018, vol. 61, no. 3, pp. 51-57.

14. Hayashi J., Kazehaya A., Muroyama K., Watkinson A.P. Preparation of activated carbon from lignin by chemical activation. Carbon, 2000, no. 38 (13), pp. 1873-1878. 
15. Tsoncheva T., Mileva A., Marinov S.P., Paneva D., Velinov N., Spassova I., Kosateva A., Kovacheva D., Petrov N. Activated carbons from used. Microporous and Mesoporous Materials, 2018, vol. 259, pp. 9-16.

16. Pallarés J., González-Cencerrado A., Arauzo I. Production and characterization of activated carbon from barley straw by physical activation with carbon dioxide and steam. Biomass and Bioenergy, 2018, vol. 115, pp. 64-73.

17. Kinle H., Bader E. Aktivnye ugli i ikh promyshlennoe primenenie [Active coals and their industrial application]. Leningrad, Khimiya Publ., 1984. $216 \mathrm{p}$.

18. Akash B.A., O'Brien W.S. The production of activated carbon from a bituminous coal. International Journal of Energy Research, 1996, vol. 20, Iss. 10, pp. 913-922.

19. Wilson J. Active carbons from coals. Fuel, 1981, vol. 60, Iss. 9, pp. 823-831.

20. Nurullina E.N., Shulaev M.V., Yakubov M.R., Sirotkin A.S., Gumerov A.M. Issledovanie protsessa polucheniya aktivirovannogo uglya iz kamennougolnogo syrya i vozmozhnosti ispolzovaniya pobochnykh produktov [Study of the process of obtaining activated carbon from coal raw materials and the possibility of using by- products]. Vestnik texnologicheskogo universiteta, 2012, vol. 15, no. 12 , pp. 237-241.

21. Olontsev V.F., Farberova E.A., Belousov K.S., Tingaev E.A. Optimalnoe upravlenie proizvodstvom aktivnogo uglya vo vrashchayushchkhsya pechakh [Optimal control over the production of active coal in rotary kilns]. Vestnik PNIPU, 2015, no. 3, pp. 51-59.

22. Teng H., Ho J.-A., Hsu Y.-F., Hsieh C.-T. Preparation of activated carbons from bituminous coals with $\mathrm{CO}_{2}$ activation. 1. Effects of oxygen content in raw coals. Industrial and Engineering Chemistry Research, 1996, no. 35 (11), pp. 4043-4049.

23. Liu D., Gao J., Cao Q., Wu S., Qin Y. Improvement of Activated Carbon from Jixi Bituminous Coal by Air Preoxidation. Energy and Fuels, 2017, vol. 31, Iss. 2, pp. 1406-1415.

24. Todes 0.M., Tsitovich 0.B. Apparaty s kipyashchim zernistym sloem (gidravlicheskie i teplovye osnovy raboty) [Apparatuses with a boiling granular layer (hydraulic and thermal bases of work)]. Leningrad, Khimiya Publ., 1981. 296 p.

25. Buevich Yu.A., Minaev G.A. Struynoe psevdoozhizhenie [Fluidized fluidization]. Moscow, Khimiya Publ., 1984. 133 p.

Received: 27 August 2019.

\section{Information about the authors}

Olga $V$. Afanaseva, Cand. Sc., head of scientific research, innovation and development department, associate professor, Kazan State Power Engineering University.

Guzel R. Mingaleeva, Dr. Sc., head of the Department of Power Engineering, Kazan State Power Engineering University. 